\title{
Ensaios sobre orientação empreendedora em uma instituição comunitária de educação superior
}

\author{
Essays on entrepreneurial orientation in a community institution of higher education
}

\section{Mara Aparecida Barnaski Fagundes ${ }^{1}$ e Fábio Dal-Soto ${ }^{2}$}

\footnotetext{
${ }^{1}$ Universidade de Cruz Alta, Brasil, Especialista em Controladoria, e-mail: marabarnaski424@gmail.com

${ }^{2}$ Universidade de Cruz Alta, Brasil, Doutorado em Administração, e-mail: dalsoto.gel@terra.com.br
}

\section{Resumo}

A orientação empreendedora se refere à atividade empreendedora no nível organizacional e sua operacionalização ocorre, basicamente, por meio da tomada de risco, proatividade e inovação. Nas universidades, essas dimensões se institucionalizam em um movimento denominado universidade empreendedora, o qual tem sido desenvolvido em diferentes contextos econômicos e sociais. A partir disso, o objetivo deste artigo é analisar a orientação empreendedora em uma Instituição Comunitária de Educação Superior (ICES), em fase inicial de transição em direção a um modelo de universidade empreendedora. Para isso, foi utilizado um estudo de caso único na Universidade de Cruz Alta (Unicruz), baseado em dados primários e secundários, especialmente entrevistas realizadas in loco. Os resultados apontam que a Unicruz passou por uma reorganização interna, o que postergou as ações empreendedoras. Ações pontuais foram determinantes para a criação de um novo mecanismo em direção à terceira missão acadêmica, a Agência de Empreendedorismo, Inovação e Transferência de Tecnologia (Start), a qual deu início a uma nova fase na Instituição.

Palavras-chave: Orientação Empreendedora. Universidade Empreendedora. Instituição Comunitária. Educação Superior.

\begin{abstract}
Entrepreneurial orientation refers to the entrepreneurial activity in the organizational level and its operationalization occurs, basically, through risk-taking, proactivity and innovation. In universities, these dimensions are institutionalized in a movement called entrepreneurial university, which has been developed in different economic and social contexts. From this, the aim of this paper is to analyze the entrepreneurial orientation in a Community Institution of Higher Education, in the initial phase of transition toward an entrepreneurial
\end{abstract}


university model. For that, a single case study was used at the University of Cruz Alta (Unicruz), based on primary and secondary data, especially interviews accomplished in loco. The results show that Unicruz underwent an internal reorganization, which delayed the entrepreneurial actions. Punctual actions were decisive in creating a new mechanism for the third academic mission, the Entrepreneurship, Innovation and Technology Transfer Agency (Start), which started a new phase in the Institution.

Keywords: Entrepreneurial Orientantion. Entrepreneurial University. Community Institution. Higher Education.

\section{Introdução}

O crescimento constante das organizações e a necessidade premente de busca de oportunidades, de inovação e de assunção de riscos tornaram imprescindível a atuação da organização como um todo no processo de empreender. Nessa ótica, a atividade empreendedora no nível organizacional é definida como orientação empreendedora, com ênfase no papel desempenhado pela estrutura da organização, na importância de construção da estratégia e no reconhecimento da importância do líder ou do sujeito que empreende (MILLER, 1983).

Em geral, as análises determinantes da orientação empreendedora (OE), bem como a sua aplicabilidade no que se refere ao desempenho, criam várias vertentes. Algumas vertentes exploram os aspectos psicológicos nos diferentes níveis da organização e analisam a influência do ambiente organizacional. Outras vertentes olham para o contexto estratégico da OE como recursos e capacidades. A maior parte das pesquisas examinam as influências de desempenho da $\mathrm{OE}$, não deixando de existir uma complementaridade natural e necessária entre os recursos que uma organização possui e os processos de tomada de decisão necessários, a fim de aproveitá-los para fins lucrativos (MILLER, 2011).

No âmbito acadêmico, a dinâmica ambiental instiga as universidades a terem maior aproximação com a sociedade como um todo. Esse desafio é histórico e está diretamente relacionado aos diferentes modelos assumidos pelas universidades em diversos lugares do mundo. A fim de atender as alterações ambientais e de interferir na própria dinâmica ambiental, as universidades movimentam-se em direção a novos modelos, com destaque para o da universidade empreendedora, o qual vem sendo utilizado em diferentes contextos econômicos e sociais.

Por conseguinte, uma universidade empreendedora não apenas promove as múltiplas medidas de apoio para o empreendedorismo, mas é também desenvolvedora de técnicas administrativas, estratégias e posturas competitivas. Com base nisso, universidades estão envolvidas em parcerias, redes e outras relações com organizações públicas e privadas que formam um 'guarda-chuva' para a interação, a colaboração, a cooperação e os elementos essenciais para a tomada de riscos, proatividade e inovação. Isso significa que a universidade empreendedora pode trabalhar em conjunto com a orientação empreendedora, a fim de facilitar a produção e a exploração de conhecimentos e tecnologias (GUERREIRO; URBANO, 2012). 
Esse contexto remete à seguinte questão de pesquisa: como se estabelece a OE em uma Instituição Comunitária de Educação Superior (ICES), em fase inicial de transição em direção a um modelo de universidade empreendedora? Logo, tem-se como objetivo analisar a OE em uma ICES, em fase inicial em direção ao modelo de universidade empreendedora. O objeto de análise é a Universidade de Cruz Alta (Unicruz), caracterizada como ICES e localizada no sul do Brasil, a qual se encontra nas fases iniciais em direção a um modelo de universidade empreendedora.

A utilização da Unicruz como objeto empírico se assenta nos seguintes argumentos: a) a trajetória singular da Instituição desenvolvida a partir da intervenção judicial, realizada no final de 2005; b) a transição de uma universidade tradicional, calcada na interação ensino, pesquisa e extensão, em direção a um modelo de universidade empreendedora, ainda em fase inicial; c) o caráter comunitário que permeia as atividades acadêmicas da Instituição, desde sua gênese. Em conjunto, essas características apontam para um caso raro ou extremo, de acordo com o fundamento lógico apresentado por Yin (2010).

Em termos de contribuição, o presente estudo encontra significativo potencial aplicado à gestão das universidades, especialmente em relação à necessidade de: a) maior equilíbrio entre a universidade e seu ambiente, a fim de reduzir os históricos reclames da sociedade em geral quanto à dissintonia do mundo acadêmico com o mundo real; b) dar mais sentido àquilo que se faz no ambiente acadêmico, por meio da aplicação do conhecimento aos problemas reais e emergentes na sociedade; c) envolver a universidade, de fato, no desenvolvimento econômico e social, assumindo uma postura protagonista nos processos de inovação e na melhoria das regiões de atuação. Em relação à teoria, o estudo contribui na aproximação entre a literatura teórica sobre orientação empreendedora e a literatura empírica acerca do fenômeno da universidade empreendedora.

No que tange ao campo empírico, as universidades passam por mudanças estratégicas e são consideradas, cada vez mais, como importante lócus para o estudo da ação estratégica (GIOIA; THOMAS, 1996). O impacto da competição no setor de educação superior é percebido no comportamento estratégico adotado pelas universidades, como na ascensão das ações empreendedoras. A realidade de mudança é diferente em organizações complexas, especialmente em universidades, onde as transformações requerem uma capacidade de mudança estruturada e o desenvolvimento de um clima interno receptivo a tais mudanças (CLARK, 1998).

A seguir, os pressupostos teóricos que sustentam a pesquisa são apresentados. $\mathrm{Na}$ sequencia, os aspetos metodológicos são mencionados, centrados no uso da técnica de estudo de caso único. Em seguida, os resultados acerca do caso em questão são abordados e, por fim, as considerações finais são apontadas.

\section{Revisão da Literatura}

A literatura que sustenta a argumentação deste artigo está organizada em dois tópicos principais: a) orientação empreendedora, que aborda a relação do conceito de OE com o 
campo de estratégia e suas principais dimensões; b) universidade empreendedora, a qual explora o desenvolvimento desse conceito na sociedade como um todo.

\subsection{Orientação Empreendedora}

Os estudos sobre orientação empreendedora ou empreendedorismo no nível organizacional tiveram como base, principalmente, o trabalho de Miller (1983). O autor reconhece a importância do líder, do sujeito que empreende, mas acrescenta o papel desempenhado pela estrutura da organização e a importância da construção da estratégia, deslocando a ênfase das capacidades inovadoras do indivíduo, que tem sido abordado na maior parte dos estudos sobre atividade empreendedora das empresas (LAZZAROTTI et al., 2015).

Antes disso, Mintzberg (1973) argumentou que o desempenho de uma empresa é, em grande parte, baseado em uma gestão composta de estratégias, atributos organizacionais (estruturas) e exigências ambientais e setoriais. A estratégia é empreendedora por natureza, uma vez que seus movimentos partem de proatividade e uma vontade de assumir riscos em novos projetos, cujos resultados são incertos. Mas foi a partir do trabalho inicial de Miller (1983) que a abordagem empresarial para a elaboração da estratégia sugeriu que as empresas empreendedoras devem utilizar a inovação na busca de oportunidades. Assim, este autor afirma que empresas empreendedoras são aquelas que assumem riscos (mantêm estratégias e recursos para resultados incertos), possuem proatividade (atuam de forma ativa no que concerne aos seus produtos, mercados e ambiente, em busca de liderança) e se expõem às inovações (introduzem novos produtos, processos e modelos de negócios).

Como um termo na análise financeira, o risco é usado no contexto do risco-retorno, onde se refere especificamente à probabilidade de uma perda ou resultado negativo. Essa foi a essência da definição que Miller e Friesen (1978) adotaram quando definiram que tomada de riscos é o grau que os gestores estão dispostos a comprometerem seus recursos, com chances de falhas dispendiosas. Assim, as empresas com uma orientação empreendedora são, muitas vezes, caracterizadas por assumirem riscos, o que acontece quando incorre em dívidas, ou fazem significativos compromissos de recursos, no interesse de obter altos retornos, aproveitando oportunidades de mercado (LUMPKIN; DESS, 1996).

Quantoà proatividade, desdeSchumpeter (1942)enfatiza-se a importância da iniciativa no processo empreendedor. Penrose (1959) argumentou que os gestores são importantes para o crescimento das empresas, os quais fornecem a visão e a criatividade, dando um toque pessoal, na expansão e na busca por oportunidades. Lieberman e Montgomery (1988) enfatizam o pioneirismo como a melhor estratégia para capitalizar essas oportunidades. Ao explorar as assimetrias dos mercados, o pioneirismo pode capturar oportunidades e gerar lucros como forma de vantagem competitiva. Assim, quando se antecipam as iniciativas, buscando novas oportunidades e participando de novos mercados, a organização torna-se associada ao empreendedorismo.

No que diz respeito à inovação, também se encontram as contribuições de Schumpeter (1942), que foi um dos primeiros a enfatizar o papel da transferência tecnológica no processo inovador. Este autor delineou a economia das empresas em duas fases: as estruturas que tinham seu crescimento interrompido, em detrimento daquelas que recebiam a introdução de novos produtos ou serviços, ou eram criadas para esse fim. A chave para este ciclo 
de atividades foi o empreendedorismo. A inserção competitiva de novas combinações inovadoras impulsionou a evolução dinâmica da economia. Assim, a inovação tornouse um fator importante para caracterizar o empreendedorismo (REYNOLDS; STOREY; WESTHEAD, 1994).

Quando a organização se engaja em atividades empreendedoras, podem estar presentes as três dimensões, ou apenas uma ou duas delas. A influência de cada uma dessas dimensões na atividade empreendedora pode ser dependente de fatores externos. Logo, é possível que essas dimensões variem independentemente e de acordo com o contexto ambiental e organizacional (LUMPKIN; DESS, 1996; WALTER; AUER; RITTER, 2006). O Quadro 1 demonstra as três dimensões e suas principais características de forma resumida.

Quadro 1 - Dimensões de uma orientação empreendedora

\begin{tabular}{|c|c|}
\hline Dimensões & Características \\
\hline $\begin{array}{l}\text { Tomada de } \\
\text { riscos }\end{array}$ & $\begin{array}{l}\text { O conceito de risco possui vários significados, dependendo do contexto de aplicação, } \\
\text { sendo frequentemente utilizado para descrever empreendedorismo. Pode-se dizer que } \\
\text { todos os negócios envolvem algum grau de risco e que não é útil pensar em termos de } \\
\text { 'absolutamente nenhum risco' (LUMPKIN; DESS, 1996). } \\
\text { Outro conceito estabelece que o risco também é ampliado na adesão de novos } \\
\text { financiamentos. Sabe-se que o risco pode ser especialmente importante para começar um } \\
\text { novo negócio, pois ele sustenta a relação curvilínea de desempenho, estabelecendo } \\
\text { melhora e manutenção nos planejamentos. Está ligado diretamente ao capital social e ao } \\
\text { fluxo de informações das organizações (MILLER, 2011). }\end{array}$ \\
\hline Proatividade & $\begin{array}{l}\text { Refere-se à forma como uma organização direciona-se a oportunidades de mercado em } \\
\text { atividades empreendedoras. A proatividade pode ser crucial para uma orientação } \\
\text { empreendedora, pois sugere uma perspectiva futura, acompanhada por atividades } \\
\text { inovadoras ou de novos empreendimentos. O oposto conceitual de proatividade é a } \\
\text { passividade, ou seja, a diferença ou incapacidade de aproveitar as oportunidades ou } \\
\text { persuadir o mercado (LUMPKIN; DESS, 1996). } \\
\text { O conceito de proatividade está presente na alavancagem de todos os recursos globais, } \\
\text { estabelecendo as relações lineares para o desempenho, e em sentido amplo no capital } \\
\text { financeiro das organizações (MILLER, 2011). }\end{array}$ \\
\hline Inovação & $\begin{array}{l}\text { Reflete a tendência da organização ao engajamento e ao apoio a novas ideias, novidade, } \\
\text { experimentação e processos criativos que podem resultar em novos produtos, serviços ou } \\
\text { processos tecnológicos. A inovação é um importante componente da orientação } \\
\text { empreendedora, pois reflete um meio pelo qual as empresas buscam novas oportunidades } \\
\text { (LUMPKIN; DESS, 1996). } \\
\text { A inovação tem um papel central no contexto de alta tecnologia e nos padrões de } \\
\text { comunicação das organizações. Também está relacionada aos recursos baseados no } \\
\text { conhecimento. Estruturas mais soltas, menos burocráticas e mais orgânicas promovem a } \\
\text { inovação de maneira natural, uma vez que a mesma não necessita de padrões claramente } \\
\text { definidos (MILLER, 2011). }\end{array}$ \\
\hline
\end{tabular}

Fonte: elaborado pelos autores.

Essas dimensões, à luz da $\mathrm{OE}$, constituem alguns dos princípios teóricos gerais que norteiam as práticas acadêmicas e se coadunam com o modelo de universidade empreendedora, cabendo aos atores principais determinarem os pilares para a sua efetivação. A seguir, as ideias centrais em torno do modelo de universidade empreendedora são apresentadas, a fim de melhor embasar a discussão aqui proposta.

\subsection{Universidade Empreendedora}

Ao longo da história, as instituições de ensino estabeleceram as regras que moldam a interação humana e contribuem para a configuração das principais fontes de crescimento na economia dos países. Esse fato é explicado por questões políticas e socioculturais, que respondem aos incentivos do governo e da indústria. Dada à complexidade das funções das universidades, estudos evidenciam o impacto econômico do ensino universitário, através de 
abordagens teóricas e metodológicas, chegando ao conceito de universidade empreendedora (GUERRERO; CUNNIGHAM; URBANO, 2015).

Como observado por Etzkowitz (1998), a universidade empreendedora é um fenômeno emergente que resulta na elaboração de uma lógica interna de desenvolvimento, expandindo os empreendimentos acadêmicos do conservador para o criativo (BOGGIO; BALLABENI; HEMENWAY, 2016). Seguindo essa tendência, as universidades têm se transformado a partir de uma universidade tradicional de pesquisa para uma universidade empreendedora com fortes laços com a indústria, incentivando assim as atividades em nível empresarial de seus acadêmicos (KALAR; ANTONCIC, 2015). Um grande número de modelos empreendedores tentam identificar os principais elementos incluídos neste processo de negócio, tais como as pessoas, o contexto, as cognições e as motivações. No entanto, esses modelos não consideram a influência de fatores ambientais, que desempenham um papel importante na configuração de atitudes pessoais e intenções empreendedoras, nem consideram as condições ou cenários empreendedores, gerados por uma economia baseada no conhecimento, como as universidades empreendedoras (GUERRERO; URBANO, 2012).

A cooperação tri-dimensional, calcada na interação universidade-governo-indústria ou hélice tríplice, é uma afirmação dos autores Etzkowitz e Leydesdorff (2000), que em seus estudos seminais abordaram que as universidades contribuem para o desenvolvimento de pesquisa e desenvolvimento em uma economia de diversas maneiras, incluindo a formação de capital humano qualificado, a transferência de tecnologia, a criação de conhecimento e a geração de empresas startups, spin-offs e spin-outs. Embora a interação entre as esferas institucionais não seja um fenômeno novo, a maneira pela qual essas interações estão se desdobrando contém elementos de novidade (PHILPOTT et al., 2011). O modelo de hélice tríplice vai além das bases dinâmicas de inovação com foco nas esferas institucionais, mas também sugere uma orientação empreendedora na criação de ambientes para essa inovação e o desenvolvimento da universidade e sua comunidade (YOON, 2015).

Logo, o aumento da importância da universidade, em termos do seu impacto sobre a economia, é observado na área do empreendedorismo (ALDRICH, 2012), a qual se centra na exploração de oportunidades baseadas no conhecimento (GUERRERO; CUNNINGHAM; URBANO, 2015). As universidades tornam-se mais empreendedoras a fim de competir, e elas se tornam mais produtivas e criativas no estabelecimento de laços entre o ensino e a pesquisa (KIRBY; GUERRERO; URBANO, 2011). Além disso, uma universidade empreendedora pode proporcionar novas alternativas para a comunidade universitária, normalmente por meio de identificação de oportunidades inovadoras (GUERRERO; URBANO, 2012). Ou seja, além de gerar profissionais qualificados e conhecimentos que podem ser comercializados tais como, patentes, licenças e acordos, as universidades produzem outras ações fomentadoras, como a geração e a atração de novos empreendimentos, os empregos, os talentos e a colaboração com agentes locais, regionais e internacionais. Como consequência, o impacto econômico das universidades ganha atenção de acadêmicos, de governos e de formuladores de políticas em todo o mundo (GUERRERO; CUNNINGHAM; URBANO, 2015).

A principal crítica sobre o modelo de hélice tríplice expressa preocupações de que a mudança para uma universidade empreendedora pode acarretar implicações negativas para as missões acadêmicas tradicionais de ensino e pesquisa. Exemplos disso incluem a falta de compromisso com publicações e registro de patentes, criação de startups que não serão sólidas fora da academia e a retenção de informações, dados e materiais em que as 
pesquisas se baseiam (CZARNITZKI; GRIMPE; PELLENS, 2015), o que torna o trabalho dispendioso e sem o propósito de disseminar conhecimento. Esses exemplos indicam que o desenvolvimento de todo o ambiente universitário em uma universidade empreendedora é uma esforço de longo prazo que deve incluir mecanismos, modelos, incentivos, práticas de gestão, comunicação adequada e atividades que se encaixam com a cultura acadêmica local existente (BIENKOWSKA; KLOFSTEN; RASMUSSEM, 2016).

\section{Método}

Esta pesquisa foi realizada por meio da abordagem qualitativa, centrando-se em um estudo de caso único, o qual, segundo Yin (2010), gera um conjunto claro de proposições e circunstâncias em que são estabelecidas condições verdadeiras e reais que podem confirmar, desafiar ou ampliar a teoria. Por isso, a pesquisa tem o ambiente natural como fonte de dados na Unicruz, a qual está presente na Região do Alto Jacuí não apenas na formação acadêmica, mas em ações desenvolvidas pela Instituição em diversas áreas, que demonstram a permanente preocupação em se fazer presente e atender as principais demandas da região.

Essas ações têm como finalidade evidenciar um compromisso social e histórico com a comunidade na qual a Unicruz se insere. São ações interdisciplinares que contribuem para a interação ensino-pesquisa-extensão. $\mathrm{O}$ destaque comunitário está presente principalmente na extensão, que possibilita a intervenção direta e de maior efetividade na sociedade. A escolha da Unicruz se deve, em parte, pela sua trajetória peculiar, marcada pela intervenção judicial realizada pelo Ministério Público, ao final de 2005, o qual destituiu a reitoria da época e nomeou um Administrador Judicial, cujo trabalho perdurou até março de 2008. Com a crise instaurada e dificuldades de toda ordem, principalmente financeira, a Instituição reduziu cada vez mais seu orçamento, cuja receita fica restrita unicamente às mensalidades dos alunos. Como salientam Guerreiro e Urbano (2014), o fenômeno empreendedor surge, historicamente, após limitações de recursos e condições imprevisíveis, criando desafios para a sobrevivência organizacional. A gestão, principalmente a financeira, exige a interação entre instituições e outras partes interessadas na região para gerar capacidade fomentadora.

Como fonte direta de dados, a pesquisa foi guiada por um roteiro semiestruturado e as entrevistas foram realizadas in loco com os principais envolvidos na disseminação da orientação empreendedora na Unicruz, tendo como ponto de partida os membros da direção. Após, as entrevistas seguiram adotando a técnica de bola de neve ou snowball. A snowball consiste na indicação pelos participantes, de novos participantes, os quais indicam outros participantes e assim sucessivamente, até atingir o ponto de saturação. O objetivo é alcançado quando os entrevistados passam a repetir os conteúdos já coletados nas entrevistas anteriores, sem acréscimo de novas informações relevantes à pesquisa (HUDELSON, 1994). As entrevistas identificaram os atores, que teoricamente, estão mais envolvidos com o processo empreendedor.

Além das fontes primárias, dados secundários foram coletados por meio do site da Unicruz, de materiais públicos e documentos internos disponibilizados pela Instituição. Ao associar as entrevistas realizadas com os dados secundários e as anotações do pesquisador, foi possível realizar a triangulação dos dados (YIN, 2010). Essa estratégia direcionou análises mais completas, pois levou em consideração mais de uma fonte de informações (FLICK, 2009). 
As entrevistas ocorreram no período de março a junho de 2017 e todos os participantes foram previamente contatados por carta de apresentação, e-mails ou telefone, a fim de agendar a colaboração com a pesquisa. Uma síntese dos participantes nas entrevistas é apresentada no Quadro 2.

\section{Quadro 2 - Entrevistas realizadas na Unicruz}

\begin{tabular}{|c|c|c|c|c|}
\hline $\begin{array}{l}\text { Entrevis- } \\
\text { tado(a) }\end{array}$ & Principais funções na Unicruz & $\begin{array}{c}\text { Ano de } \\
\text { admissão } \\
\text { na Unicruz }\end{array}$ & $\begin{array}{c}\text { Data da } \\
\text { entrevista }\end{array}$ & $\begin{array}{l}\text { Tempo } \\
\text { de } \\
\text { duração }\end{array}$ \\
\hline 1 & $\begin{array}{l}\text { Reitora desde 2014. Pró-reitora de Pós-graduação, } \\
\text { Pesquisa e Extensão de } 2011 \text { a 2014. }\end{array}$ & 2000 & $09 / 03 / 2017$ & $45: 14$ \\
\hline 2 & $\begin{array}{l}\text { Coordenador pró-tempore do Projeto Extensão Produtiva e } \\
\text { Inovação de } 2012 \text { a } 2015 \text {. Coordenadora geral da Agência } \\
\text { Start desde } 2015 \text {. }\end{array}$ & 2000 & $21 / 03 / 2017$ & $28: 52$ \\
\hline 3 & $\begin{array}{l}\text { Pró-Reitor de Pós-Graduação, Pesquisa e Extensão desde } \\
\text { 2017. Presidente do Conselho Curador da Fundação } \\
\text { Universidade de Cruz Alta desde } 2017 .\end{array}$ & 2011 & $22 / 03 / 2017$ & $1: 02: 40$ \\
\hline 4 & $\begin{array}{l}\text { Coordenadora do Curso de Jornalismo desde } 2017 . \\
\text { Membro do Conselho Universitário desde 2015. }\end{array}$ & 2006 & $24 / 03 / 2017$ & $53: 38$ \\
\hline 5 & $\begin{array}{l}\text { Presidente do Conselho Diretor e Presidente da Fundação } \\
\text { Universidade de Cruz Alta desde 2013. Coordenadora } \\
\text { geral da Incubadora e Aceleradora de Negócios Sociais } \\
\text { desde } 2015 \text {. }\end{array}$ & 2003 & $03 / 04 / 2017$ & $50: 46$ \\
\hline 6 & $\begin{array}{l}\text { Pró-Reitor de Administração desde 2013. Coordenador } \\
\text { adjunto da Agência de Empreendedorismo, Inovação e } \\
\text { Transferência de Tecnologia desde } 2015 \text {. }\end{array}$ & 2003 & $12 / 04 / 2017$ & $58: 28$ \\
\hline 7 & $\begin{array}{l}\text { Representante docente do Centro de Ciências Humanas e } \\
\text { Sociais desde 2017. Coordenadora do Curso de Ciências } \\
\text { Contábeis desde } 2013 \text {. }\end{array}$ & 2004 & $11 / 05 / 2017$ & $52: 48$ \\
\hline 8 & $\begin{array}{l}\text { Membro da Coordenação do Projeto Profissão Catador } \\
\text { desde } 2013 \text {. }\end{array}$ & 2012 & $18 / 05 / 2017$ & $1: 01: 55$ \\
\hline 9 & $\begin{array}{l}\text { Membro do Núcleo Docente Estruturante do Curso de } \\
\text { Agronomia. Responsável técnica pela área experimental do } \\
\text { laboratório de sementes desde } 2014 \text {. }\end{array}$ & 1992 & $19 / 05 / 2017$ & $51: 29$ \\
\hline 10 & $\begin{array}{l}\text { Coordenador da Área Experimental. Coordenador do } \\
\text { laboratório de Entomologia desde } 2015 .\end{array}$ & 2014 & $22 / 05 / 2017$ & $59: 35$ \\
\hline 11 & Gestora da Secretaria Acadêmica desde 2014. & 2014 & $25 / 5 / 2017$ & $45: 25$ \\
\hline 12 & $\begin{array}{l}\text { Coordenador de pesquisa desde 2013. } \text { Membro da } \\
\text { Comissão do Plano de Desenvolvimento Institucional } \\
\text { desde 2017. }\end{array}$ & 2009 & $25 / 05 / 2017$ & $1: 00: 37$ \\
\hline 13 & $\begin{array}{l}\text { Coordenador do Curso de Engenharia da Produção. } \\
\text { Membro do conselho do Centro de Ciências Humanas e } \\
\text { Sociais desde } 2016 \text {. }\end{array}$ & 2016 & $01 / 06 / 2017$ & $38: 30$ \\
\hline
\end{tabular}

Fonte: elaborado pelos autores.

As entrevistas foram gravadas e posteriormente transcritas, para que assim pudessem passar por refinamento analítico, colocando as informações em séries diferentes (MILES; HUBERMAN, 1994). As transcrições geraram narrativas que segundo Pollak (1989), ao se tomarem objeto de investigação é importante ressaltar que as narrativas constituem construções discursivas marcadas pelo olhar retrospectivo. A seguir, foi desenvolvida uma estrutura teórica para a descrição da pesquisa, o que, segundo Yin (2010), demonstra que a finalidade original e explícita do estudo é de abordagem descritiva e ajuda a identificar as ligações causais analisadas. Esse desenho metodológico construiu o desenvolvimento das considerações no âmbito do binômio orientação empreendedora e universidade empreendedora, o que resultou em dois tópicos como eventos principais e apresentados a seguir: a) a trajetória recente e as contrariedades; b) o começo: os primeiros mecanismos.

\section{0 Caso da Unicruz}

Os laços entre universidade e indústria têm provocado mudanças organizacionais e moldam experiências nas últimas duas décadas. O ambiente acadêmico está se transformando 
em resposta ao crescimento de um paradigma empreendedor, que sublima a capitalização do conhecimento. As universidades tornam-se cada vez mais dispostas a explorarem resultados para aumentar a sua renda interna e se adaptarem a ambientes mais competitivos, usando a comercialização da propriedade intelectual, como patentes, licenciamentos ou participação de startups empreendedoras como meio de geração de receitas (LAM, 2010).

Diante desse cenário, transformado e transformador, está a Unicruz como uma ICES. Essa condição tem na sua constituição a forma de fundação sem fins lucrativos, transparência administrativa, participação na comunidade e uma gestão composta de Conselho Diretor, Conselho Curador e Conselho Universitário. Em termos de gestão, a Unicruz possui uma gestão administrativa compartilhada entre mantenedora (Fundação) e mantida (Instituição). A mantenedora é responsável pela gestão financeira e a mantida pelos demais assuntos administrativos estabelecidos pela Pró-Reitoria de Administração, que é um dos principais elos entre mantida e mantenedora.

A Instituição integra o Consórcio das Universidades Comunitárias Gaúchas (Comung) desde 1994 e o Conselho Regional de Desenvolvimento (Corede) do Alto Jacuí, onde está inserida em sua localização geográfica. O Corede Alto Jacuí é um dos 28 Conselhos Regionais de Desenvolvimento do Rio Grande do Sul e a UNICRUZ é sua gestora técnica. Também está incluída no Programa de Estímulo à Reestruturação e ao Fortalecimento das Instituições de Ensino Superior (PROIES), que assegura condições para as atividades de entidades mantenedoras de instituições de ensino superior, auxiliando na recuperação tributária e de moratórias de dívidas, dispondo sobre esses procedimentos a oferta de bolsas e a seleção de bolsistas. Organiza-se em dois grandes centros: Centro de Ciências Humanas e Sociais (CCHS) e Centro de Ciências da Saúde e Agrárias (CCSA). Cada centro reúne áreas e cursos, que formam uma estrutura acadêmica-administrativa, sob a coordenação de um diretor.

A fim de seguir a lógica da análise, é preciso compreender que a Unicruz passou por uma reorganização estrutural que se desenhou ao longo de um período de nove anos, de 2005 a 2014. À luz da orientação empreendedora, compreende-se que as atitudes dos atores principais envolvidos no processo tiveram um papel fundamental nessa reorganização. Ao levar em consideração essas atitudes comportamentais voltadas para o empreendedorismo, indicadores puderam ser usados e identificados através de documentação, registro em arquivos, entrevistas, observações e artefatos físicos, que contam a trajetória da Instituição. A identificação ocorreu baseada nas dimensões que são amplamente reconhecidas como fatores que compõem a $\mathrm{OE}$, tais como: processos de tomada de decisões, com atitudes voltadas para assumir riscos, muitas vezes na busca por recursos financeiros; pró-atividade, no que tange a uma visão sistêmica; e busca constante por inovação.

\subsection{A Trajetória Recente e as Contrariedades}

Em novembro de 2005, a Unicruz sofreu um divisor de águas. A operação “Toga" culminou com a destituição da Reitoria e os administradores foram afastados das funções, a pedido do Ministério Público do Estado do Rio Grande do Sul. As suspeitas indiciavam sobre uma gestão temerária. O grupo, na época, foi acusado de cometer vários delitos, como estelionato, apropriação indébita e fraudes contábeis. No momento da intervenção, a Instituição encontrava-se em situação caótica apresentando endividamento fiscal, bancário e com fornecedores de energia elétrica e telefonia; salários atrasados; a maioria dos cursos 
sem renovação de reconhecimento e um enorme passivo trabalhista. As dívidas chegavam a $\mathrm{R}$ \$ 39 milhões e o déficit mensal girava em torno de $\mathrm{R}$ \$ 1 milhão. No período de novembro de 2005 a dezembro de 2007, vigência da Administração Judicial, ocorreu a reforma estatutária que buscou resolver as questões das dívidas, através de parcelamentos e implementações de medidas que viessem permitir a obtenção de regularidade fiscal.

Esse processo culminou com a separação da gestão da mantenedora e da mantida. A Unicruz, em seu estatuto, previa a acumulação de cargos, em que o reitor também exercia as funções de presidente da Fundação, presidente do Conselho Diretor e presidente do Conselho Universitário. A reestruturação pedagógica, administrativa e financeira da Universidade resultou na divisão organizacional entre Fundação (mantenedora) e Universidade (mantida) e a posse dos novos gestores, tanto da mantenedora quanto da mantida, ocorreu em abril de 2008 .

Em março de 2009, a Instituição passou por avaliação externa do MEC e os resultados apontaram para as fragilidades decorrentes do período vivenciado. Os anos de 2008, 2009 e 2010 permitiram avanços na reorganização institucional. Em novembro de 2011, a Instituição passou por nova avaliação externa do MEC, que resultou em avaliação satisfatória para recredenciamento da mesma (UNICRUZ, 2013). No período 2006 a 2010, os esforços se concentraram em atender a demanda dos mestrados e doutorados.

A partir dessas contrariedades, uma nova era começou a ser formulada para que a universidade voltasse a ser reconhecida como elo essencial da comunidade. A Unicruz e a Fundação Universidade de Cruz Alta estrategicamente começaram a participar de comissões e alianças, garantindo fomentos e manutenção de crescimento. Em 2014, com a eleição da nova reitoria, o empreendedorismo passou a fazer parte dos objetivos institucionais e a ideia era trabalhar o modelo de hélice tríplice, com a aproximação do poder público, das empresas e tendo a universidade como articuladora. Essa trajetória está sintetizada na seguinte entrevista:

“Então, eu considero, em 2005, tivemos essa grande mudança, e nós fomos até 2012, 2013 num período de organização, e tanto organização financeira da Instituiç̧ão, quanto organização pedagógica. Nós tínhamos cursos que não tinham reconhecimento, nós estávamos sem a documentação necessária, sem a chancela, podemos dizer assim, dos órgãos que regulamentam o ensino superior. Então a gente precisou de todo esse tempo para uma grande organização. A partir de 2013, 2014, aí é como se as coisas não estivessem resolvidas, mas elas estão mapeadas, negociadas, a partir desse momento aí sim você consegue trazer alguns investimentos para a Instituição, e pensar, bom agora é o momento da gente, bom é um outro momento da caminhada. Foi o momento de implementar algumas ações, várias coisas novas dentro da Instituição, e é isso que a gente visualiza nesse momento" (Entrevistado 5).

Como apontam Audy e Morosini (2006), a universidade transforma-se de uma instituição centrada basicamente no ensino para uma instituição que combina seus recursos 
e potenciais na área de pesquisa como uma nova missão, voltada para o desenvolvimento econômico e social da comunidade onde atua, estimulando o surgimento de ambientes de inovação e disseminando uma cultura empreendedora.

Dada essa busca, impulsionada por transformações ambientais, setoriais e de seus recursos e por ser uma ICES, a Unicruz entendeu que não se encontrava sozinha nesse ambiente. A troca de informações e a busca por recursos passaram a ser constantes, apesar do modelo burocrático que mostrava o empreendedorismo de forma implícita, através da equipe que trabalhava incessantemente para o crescimento da Instituição. As ações já existiam, mas eram pontuais, como relata outra entrevista:

"Então, o que eu vejo hoje, a universidade, ela talvez deveria ter entrado mais cedo nesse viés de instituição empreendedora e com um olhar específico à isso, porque as ações eram um pouco menores. Por outro lado, nós temos todo um histórico institucional, em momentos institucionais que não permitiram que isso acontecesse, então não foi uma questão de negligenciar algo, mas pelo contrário, foi porque não havia como ter uma caminhada nesse sentido" (Entrevistado 3).

A orientação empreendedora encontra-se em fase inicial e na busca de adesão interna, mas é através das parcerias externas que essa consolidação ganha corpo ao transcorrer do tempo, mostrando as dimensões de proatividade, inovação e trabalhando os riscos, principalmente os riscos financeiros.

Como salientam Covin e Slevin (1988) e Covin, Green e Slevin (2006), a OE representa um construto unidimensional no qual as dimensões citadas colaboram de forma semelhante para sua existência, identificando como empreendedora a organização que apresenta altos níveis de todas essas dimensões.

\subsection{O Começo: Os Primeiros Mecanismos}

Nos últimos anos, a Instituição promoveu um amplo programa cujo principal objetivo foi redimensionar sua infraestrutura, com vista a torná-la mais eficiente organizacional e economicamente. As ações, embora em fase inicial, já demonstram consistência.

Em parte, essas ações estão vinculadas à Agência de Empreendedorismo, Inovação e Transferência de Tecnologia (Start), que faz parte da Pró-Reitoria de Pós-Graduação, Pesquisa e Extensão.

A Start começou a ser pensada e idealizada como meta do Plano de Desenvolvimento Institucional (PDI), exercício 2013-2017, o que se coaduna com a ideia de que o empreendedorismo parte da criação de novas estratégias nas organizações existentes e representa um dos principais motores do crescimento econômico, com íntima relação entre empreendedorismo e desenvolvimento local e regional (RASMUSSEN; SORHEIM, 2006).

Sendo assim, no final de 2015, foi criada a Start para dar vasão à demanda empreendedora, concentrando as ações que até então eram pontuais. 
A Agência em questão possui regulamento próprio que institui seis unidades, as quais possuem o objetivo de operacionalizar as ações na área de empreendedorismo, fomentos e recursos. As unidades que compõem a Start seguem descritas de forma resumida no Quadro 3.

Quadro 3 - Unidades operacionais da Start

\begin{tabular}{|c|c|}
\hline Unidades & Características \\
\hline $\begin{array}{l}\text { Escritório de } \\
\text { Empreendedorismo }\end{array}$ & $\begin{array}{l}\text { Promove ações para a disseminação da cultura empreendedora, inclusive nos municípios } \\
\text { do Alto Jacuí. Oferece oficinas, palestras, minicursos e encontros. Forma um elo entre } \\
\text { acadêmicos, professores, egressos, empresas e comunidade. }\end{array}$ \\
\hline $\begin{array}{l}\text { Núcl } \\
\text { Capta } \\
\text { Rec }\end{array}$ & $\begin{array}{l}\text { Faz a mediação entre os editais lançados pelos órgãos financiadores e o corpo docente, } \\
\text { delimitando quais podem ser atendidos pela Instituição e quais devem aguardar } \\
\text { demanda. O trabalho auxilia o corpo docente nas determinações dos órgãos } \\
\text { fomentadores, sua documentação e exigências que regem o ensino superior brasileiro. }\end{array}$ \\
\hline $\begin{array}{l}\text { Núcl } \\
\text { Exten } \\
\text { Produ } \\
\text { Inov }\end{array}$ & $\begin{array}{l}\text { Está presente em quatorze municípios da região do Alto Jacuí, contando com uma vasta } \\
\text { área de atuação. Agrega estagiários em um trabalho de coleta de dados e modelagem de } \\
\text { prestação de serviços para atender as demandas das empresas de pequeno e médio porte. } \\
\text { Oferece capacitações específicas em parceria com o Serviço Brasileiro de Apoio às } \\
\text { Micro e Pequenas Empresas (SEBRAE). }\end{array}$ \\
\hline $\begin{array}{r}\text { Incub } \\
\text { Acel } \\
\text { Tecnol } \\
\text { Negócic }\end{array}$ & $\begin{array}{l}\text { lcubadora de empresas do segmento de empreendimentos sociais e associativismo. } \\
\text { brange vários projetos com viés social e geração de trabalho e renda. Está presente em } \\
\text { eis municípios e atende uma demanda global de destinação de resíduos sólidos, ainda } \\
\text { luito dependente de uma conscientização sustentável. }\end{array}$ \\
\hline $\begin{array}{l}\text { Área Experimental } \\
\text { Agrícola }\end{array}$ & $\begin{array}{l}\text { cerias entre universidade e empresas do agronegócio. Possui mais de } \\
\text { as alocadas e atende demandas internas e externas. }\end{array}$ \\
\hline $\begin{array}{l}\text { Polo de Inovação } \\
\text { Tecnológica do } \\
\text { Alto Jacuí }\end{array}$ & $\begin{array}{l}\text { Surgiu com os avanços do modelo de hélice tríplice e da universidade empreendedora no } \\
\text { Brasil na década de } 90 \text {. Atende as demandas estabelecidas pelo governo do Estado do } \\
\text { Rio Grande do Sul com altos níveis de pesquisa e desenvolvimento. }\end{array}$ \\
\hline
\end{tabular}

Fonte: elaborado pelos autores.

\subsection{Síntese dos Resultados}

Embora o conceito de universidade empreendedora tenha propósitos claros, há alguns aspectos que demandam melhor entendimento para a sua implementação, tendo em vista que o conceito em questão é mais amplo do que apenas a incorporação de uma terceira tarefa e de novos modelos de governança.

$\mathrm{Na}$ abordagem da hélice tríplice, a universidade possui papel fundamental como fonte de empreendedorismo, receitas, tecnologia e investigações críticas. Nessa abordagem, as universidades empreendedoras têm papel-chave por meio da transferência de tecnologia, da incubação de novas empresas e da condução de esforços nas renovações regionais (SAM; van der SIJDE, 2014).

Na Unicruz, essa perspectiva inicial gera interações futuras e em fase de planejamento. A maioria dos atores envolvidos não menciona a preocupação da capitalização e da geração de receita dessas ações em um primeiro momento, o que indica que a implementação de um modelo de universidade empreendedora é um esforço de longo prazo e institui muitas mudanças.

A fase inicial liga a Instituição ao conceito estratégico da orientação empreendedora e permeia os primeiros passos rumo a um modelo de universidade empreendedora. Ao lançar as ações empreendedoras encontradas dentro das unidades da Start, percebe-se que grande parte dos projetos adotam doses de proatividade e inovação e que a tomada de risco ainda é pouco mensurada, ficando concentrada no Núcleo de Captação de Recursos. 
O Quadro 4 sintetiza a trajetória recente da Unicruz, voltada estrategicamente para uma orientação empreendedora.

Quadro 4 - Síntese da trajetória recente da Unicruz voltada para uma orientação empreendedora

\begin{tabular}{|c|c|c|}
\hline Proatividade & Inovação & Tomada de risco \\
\hline 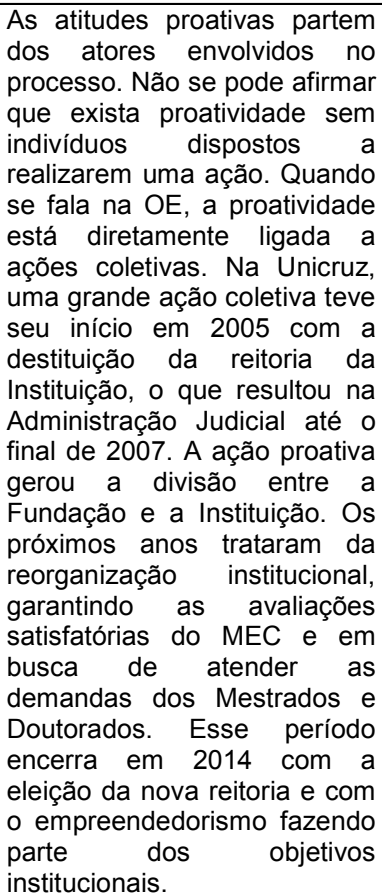 & $\begin{array}{l}\text { Inovação é um sinônimo de } \\
\text { criatividade. Quando se passa } \\
\text { por uma reorganização } \\
\text { interna, como ocorrido na } \\
\text { Unicruz, os esforços pela } \\
\text { busca de fomentos exigem } \\
\text { altas doses de inovação por } \\
\text { parte dos atores. A inovação } \\
\text { também pode ser encontrada } \\
\text { em processos, projetos e } \\
\text { setores considerados } \\
\text { burocráticos. Essas ações } \\
\text { inovadoras levaram a } \\
\text { Instituição, em 2015, a criar a } \\
\text { Start, concentrando as ações } \\
\text { empreendedoras, por meio de } \\
\text { seis unidades. A Start é uma } \\
\text { articuladora e se enlaça a } \\
\text { todos os setores da Instituição } \\
\text { e seu entorno. Também está } \\
\text { presente na mensuração e } \\
\text { avaliação de resultados, fator } \\
\text { determinante para diminuir } \\
\text { riscos, principalmente os riscos } \\
\text { financeiros. }\end{array}$ & $\begin{array}{l}\text { Apesar de estar diretamente } \\
\text { relacionada aos riscos } \\
\text { financeiros que } \text { uma } \\
\text { organização pode assumir, } \\
\text { quando se fala no conceito em } \\
\text { sentido amplo estão presentes } \\
\text { o risco social (a imagem da } \\
\text { Instituição) e o risco psicológico } \\
\text { (o envolvimento de seus } \\
\text { colaboradores). A Unicruz se } \\
\text { preocupa em avaliar esses três } \\
\text { tipos de risco na criação de } \\
\text { seus projetos, procurando dar } \\
\text { visibilidade primeiramente às } \\
\text { ações empreendedoras e } \\
\text { posteriormente nomeando } \\
\text { unidades representativas. Um } \\
\text { exemplo é o projeto Profissão } \\
\text { Catador, cujas ações iniciadas } \\
\text { em 2006 deram origem a } \\
\text { INATECSOCIAL, criada em } \\
\text { 2015, a qual agrega todos os } \\
\text { projetos do segmento social. } \\
\text { Embora ainda não haja uma } \\
\text { preocupação com lucros, os } \\
\text { projetos passam pelo Núcleo de } \\
\text { Captação de Recursos, que faz } \\
\text { a triagem de sua viabilidade. }\end{array}$ \\
\hline
\end{tabular}

Fonte: elaborado pelos autores.

Apesar das diferentes abordagens, tanto a universidade empreendedora quanto a orientação empreendedora possuem similaridades no processo de transformação da universidade, como a obtenção de fontes variadas de renda, a postura empreendedora da instituição, especialmente dos gestores e pesquisadores, e o impacto no desenvolvimento da região (ETZKOWITZ et al., 2000). Por outro lado, é sensato que nem todos os projetos se encaixam no modelo empreendedor. Essa trajetória representa uma mudança de paradigma e não pode ser vista como conclusiva, mas suas evidências permeiam as dimensões de proatividade, inovação e tomada de riscos.

\section{Considerações Finais}

O presente artigo procurou analisar a orientação empreendedora em uma ICES em fase inicial em direção a um modelo de universidade empreendedora. Assim, buscou-se identificar as atividades empreendedoras estabelecidas entre a universidade e seu meio, por meio das três dimensões da orientação empreendedora: tomada de risco, proatividade e inovação. A partir da revisão da literatura, dos principais pontos das entrevistas e dos documentos disponibilizado pela Unicruz, foram descritos dois momentos cruciais: a) a trajetória recente e as contrariedades; b) o começo: os primeiros mecanismos.

No primeiro momento, foram observados circunstâncias e eventos que marcaram a história recente da Instituição estudada. A principal delas foi a intervenção judicial em 2005, em virtude de gestão temerária. A experiência dividiu a Universidade em momentos antes e depois desse evento e reforçou a ideia de que uma reorganização estatutária precisava ser

feita. Essa reestruturação ocorreu nesse período, além de muitas ações desenvolvidas na área 
de empreendedorismo, porém de forma pontual. Parcerias e alianças passaram a constituir uma principal motivação e pesquisas e projetos começaram a ter uma representatividade na captação de recursos externos.

No segundo momento, destaca-se a criação da Start para operacionalização das ações empreendedoras. A Start desempenha o papel de articuladora interna e externa, por meio de suas seis unidades, e agrega inúmeros projetos que reforçam a imagem comunitária da Instituição. Percebe-se, portanto, a ideia da hélice tríplice, como apontado por Clark (1998), na qual as evidências mostram que a Instituição tornou-se mais adaptativa às demandas impostas pelo ambiente externo. Além disso, a Instituição trabalha de forma conjunta com as três dimensões basilares da orientação empreendedora, adotando a proatividade, inovação e tomada de risco como norteadoras dessas ações. Nesse sentido, a Unicruz incentiva projetos empreendedores que envolvem unidades acadêmicas de diferentes áreas do conhecimento, com foco no entorno da universidade.

Sobre o caso escolhido, destaca-se que a Unicruz encontra-se em fase inicial de transição em direção a um modelo de universidade empreendedora, o que limita a evidenciação de experiências mais avançadas ou de um maior número de mecanismos na implementação da terceira missão acadêmica. Casos de sucesso ou de maior trajetória em busca de um modelo de universidade empreendedora podem contribuir com novos subsídios acerca do estabelecimento da orientação empreendedora no ambiente acadêmico.

Na lógica da academia seguindo o campo empírico, a ascensão relativamente recente da orientação empreendedora no ambiente acadêmico, ocorrida em diversas partes do mundo, indica novas indagações e curiosidades, para melhor elucidá-la em diferentes contextos econômicos e sociais. Em consequência, há várias questões a respeito desse fenômeno que merecem investigação, ainda geram dúvidas ou suscitam novas discussões através de diferentes lentes e combinações teóricas, como o impacto no desenvolvimento regional e a contextualização de universidades empreendedoras nos ambientes naturais da sociedade e da economia para a produção do conhecimento e dos sistemas de inovação.

\section{Referências}

ALDRICH, H.E. The emergence of entrepreneurship as an academic field: a personal essay on institutional entrepreneurship. Research Policy, v. 41, n. 7, p. 1240-1248, 2012.

AUDY, J.L.N.; MOROSINI, M.C. Inovação e Empreendedorismo na Universidade. 1a ed. Porto Alegre: EDIPUCRS, 2006.

BIENKOWSKA, D.; KLOFSTEN, M.; RASMUSSEN, E. PhD students in the entrepreneurial university - Perceived support for academic entrepreneurship. European Journal of Education, v. 51, n. 1, p. 55-72, 2016.

BOGGIO, A.; BALLABENI, A.; HEMENWAY, D. Basic research and knowledge production modes: a view from the Harvard Medical School. Science, Technology e Human Values, v. 41, n. 2, p. 163-193, 2016. 
CLARK, B.R. Creating Entrepreneurial Universities: Organization Pathways of Transformation. United Kingdom: Emerald, 1998.

COVIN, J.G.; SLEVIN, D.P. The influence of organization structure on the utility of an entrepreneurial top management style. Journal of Management Studies, v. 25, n. 3, p. 217234, 1988.

; GREEN, K.M.; SLEVIN, D.P. Strategic process effects on the entrepreneurial orientation-sales growth rate relationship. Entrepreneurship: Theory \& Practice, v. 30, n. 1, p. 57-81, 2006.

CZARNITZKI, D.; GRIMPE, C.; PELLENS, M. Access to research inputs: open science versus the entrepreneurial university. Journal of Technology Transfer, v. 40, n. 6, p. 1050-1063, 2015.

ETZKOWITZ, H. The norms of entrepreneurial science: cognitive effects of the new university-industry linkages. Research Policy, v. 27, n. 2, p. 109-123, 1998.

; LEYDESDORFF, L. The dynamics of innovation: from national systems and "Mode2" to a triple helix of University-Industry-Government relations. Research Policy, v. 29, n. 2, p. 109-123, 2000.

et al. The future of the university and the university of the future: evolution of ivory tower to entrepreneurial paradigm. Research Policy, v. 29, n. 2, p. 313-330, 2000.

FLICK, U. Desenho da pesquisa qualitativa. Porto Alegre: Artmed, 2009.

GIOIA, D.A.; THOMAS, J.B. Identity, image and issue interpretation: sensemaking during strategic change in academia. Administrative Science Quarterly, v. 41, n. 3, p. 370-403, 1996.

GUERRERO, M.; CUNNINGHAM, J.A.; URBANO, D. Economic impact of entrepreneurial universities' activities: an exploratory of the United Kingdom. Research Policy, v. 44, n. 3, p. 748-764, 2015.

; URBANO, D. The development of an entrepreneurial university. Journal of Technology Transfer, v. 37, n. 1, p. 43-74, 2012.

Academics' start-up intentions and knowledge filters: an individual perspective of the knowledge spillover theory of entrepreneurship. Small Business Economy, v. 43, n. 1, p. 57-74, 2014.

HUDELSON, P.M. Qualitative research for health programmes. Geneva: World Health Organization (WHO) - Division of Mental Health, 1994.

KALAR, B.; ANTONCIC, B. The entrepreneurial university, academic activities and technology and knowledge transfer in four European countries. Technovation, v. 36-37, p. 1-11, 2015. 
KIRBY, D.A.; GUERRERO, M.; URBANO, D. Making universities more entrepreneurial: development of a model. Canadian Journal of Administrative Science, v. 28, n. 3, p. 302316, 2011.

LAM, A. From 'Ivory tower traditionalists' to 'Entrepreneurial scientists'? Academic scientists in fuzzy university-industry boundaries. Social Studies of Science, v. 40, p. 307340, 2010.

LAZZAROTTI, F. et al. Orientação empreendedora: Um estudo das dimensões e sua relação com desempenho em empresas graduadas. Revista de Administração Contemporânea, v. 19, n. 6, p. 673-695, 2015.

LIEBERMAN, M.B.; MONTGOMERY, D.B. First-mover advantages. Strategic Management Journal, v. 9, n. S1, p. 41-58, 1988.

LUMPKIN, G.T.; DESS, G.G. Clarifying the entrepreneurial orientation construct and linking it to performance. Academy of Management Review, v. 21, n. 1, p. 135-172, 1996.

MILES, M.B.; HUBERMAN, A.M. Qualitative data analysis: an expanded sourcebook. Thousand Oaks, CA: Sage, 1994.

MILLER, D.; FRIESEN, P.H. Archetypes of strategy formulation. Management Science, v. 24, n. 9, p. 921-933, 1978.

. The correlates of entrepreneurship in three types of firms. Management Science, v. 29, n. 7, p. 770-791, 1983.

. Miller (1983) revisited: A reflection on EO research and some suggestions for the future. Entrepreneurship: Theory \& Practice, v. 35, n. 5, p. 873-894, 2011.

MINTZBERG, H. Strategy-making in three modes. California Management Review, v. 16, n. 2, p. 44-53, 1973.

PENROSE, E.T. The theory of the growth of the firm. New York: Wiley, 1959.

PHILPOTT, K. et al. The entrepreneurial university: examining the underlying academic tensions. Technovation, v. 31, n. 4, p. 161-170, 2011.

POLLAK, M. Memória, esquecimento e silêncio. Revista Estudos Históricos, v. 2, n. 3, p. 3-15, 1989.

RASMUSSEN, E.; SORHEIM, R. Action-based entrepreneurship education. Technovation, v. 26, n. 2, p. 185-194, 2006.

REYNOLDS, P.; STOREY, D.J.; WESTHEAD, P. Cross national comparisons of the variation in new firm formation rates. Regional Studies, v. 28, n. 4, p. 443-456, 1994. 
SAM, C.; van der SIJDE, P. Understanding the concept of the entrepreneurial university from the perspective of higher education models. Higher Education, v. 68, n. 6, p. 891-908, 2014.

SCHUMPETER, J.A. Capitalism, socialism and democracy. New York: Harper \& Row, 1942.

Universidade de Cruz Alta (Unicruz). Plano de Desenvolvimento Institucional (PDI) 20132017. Cruz Alta - RS, 2013.

WALTER, A.; AUER, M.; RITTER, T. The impact of network capabilities and entrepreneurial orientation on university spin-off performance. Journal of Business Venturing, v. 21, n. 4, p. 541-567, 2006.

YIN, R.K. Estudo de caso - Planejamento e Métodos. 4. ed. Porto Alegre: Bookman, 2010.

YOON, J. The evolution of South Korea's innovation system: moving towards the triple helix model? Scientometrics, v. 104, n. 1, p. 265-293, 2015. 